\title{
Somatic embryogenesis from young inflorescences of the giant bamboo Dendrocalamus asper (Schult f.) Backer ex Heyne
}

Thiago Sanches Ornellas ( $\nabla$ thisorn@gmail.com )

Universidade Federal de Santa Catarina Centro de Ciencias Agrarias https://orcid.org/0000-0002-66380937

\section{Yohan Fritsche}

Federal University of Santa Catarina: Universidade Federal de Santa Catarina

\section{Edison Cardona Medina}

Federal University of Santa Catarina: Universidade Federal de Santa Catarina

\section{Miguel Pedro Guerra}

Federal University of Santa Catarina: Universidade Federal de Santa Catarina

\section{Research Article}

Keywords: Bamboo spikelet, callus induction, micropropagation, secondary somatic embryogenesis

Posted Date: November 30th, 2021

DOI: https://doi.org/10.21203/rs.3.rs-1036356/v1

License: (c) (i) This work is licensed under a Creative Commons Attribution 4.0 International License. Read Full License 


\section{Abstract}

Bamboos are an important worldwide non-timber forest product with current rising interest due to their environmentally friendly applications. Besides the consolidated uses of the sweet shoots and culms for structural uses, Dendrocalamus asper is an imposing ornamental bamboo for horticulture. The present work aimed to establish in vitro calli culture and plant regeneration through somatic embryogenesis starting from young inflorescences of the giant bamboo, D. asper. Pre-anthesis inflorescences were collected, disinfested, and subjected to callus induction on MS basal medium supplemented by $0 \mu \mathrm{M}, 9$ $\mu \mathrm{M}, 18 \mu \mathrm{M}, 27 \mu \mathrm{M}$, and $36 \mu \mathrm{M}$ of 2,4-D in combination with $9 \mu \mathrm{M}$ of 2-iP or $9 \mu \mathrm{M}$ Kin. The different obtained calli types were characterized and subcultured in $0 \mu \mathrm{M}, 4.5 \mu \mathrm{M}, 9 \mu \mathrm{M}$, and $18 \mu \mathrm{M}$ of 2,4-D in combination with $9 \mu \mathrm{M}$ of both cytokinins for multiplication and differentiation. Additionally, the explant incision and its inoculation orientation onto culture media were tested for callus induction improvement. The 2,4-D was essential for callus induction, and its combination with both cytokinins resulted in embryogenic callus induction and further somatic embryos regeneration. The subsequent reduction of this auxin to $4.5 \mu \mathrm{M}$ resulted in somatic embryo maturation. Somatic embryos transferred to a plant growth regulator-free medium resulted in plantlet conversion. The present work showed the feasibility of using inflorescences as explants and the efficiency of using the 2-iP in combination with 2,4-D to callus induction and in vitro bamboo plant regeneration through somatic embryogenesis.

\section{Key Message}

Immature inflorescences of the giant bamboo are feasible explants for in vitro callus induction and somatic embryogenesis.

\section{Introduction}

Despite the "bamboo" generic term, the Bambusoideae subfamily (Poaceae family) comprises a wide diversity with more than 1680 species currently identified (Soreng et al. 2017; Clark and Oliveira, 2018), displaying a broad range of applications. The increasing worldwide bamboo interest is due to their economic and environmental sustainability, as they are noteworthy ecosystem service providers (cultural, supporting, provisioning, and regulating) (Paudyal et al. 2019). Although practically every part of the bamboo is useful for food, medicine, handicrafts, construction, biomass, and primal matter for industry (Liese et al. 2015; Akinlabi et al. 2017), the most elegant application of bamboos is as the whole plant in the landscape ornamentation. Due to the spiritual or cultural connotation, or only because of the unique giant grass characteristics, the ornamental use of bamboos on gardens promotes benefits on both the physiological and psychological levels for the people (Wang et al. 2021; Zheng et al. 2021).

Dendrocalamus asper is a tropical non-invasive bamboo with majestic culms that can reach up to $30 \mathrm{~m}$ of height and more than $15 \mathrm{~cm}$ of diameter. Every year, the shoots sprouting is an eye-catching phenomenon, not just because of their huge dimension, but also because they provide a colorful-dynamic effect on the gardens. When those shoots emerge from the soil, they show dark-purple leaves. They are 
protected by bronzed sheaths, which fall after the rapid shoot elongation ( $+50 \mathrm{~cm} /$ day), revealing a whitish-brown velvety hair in basal nodes and conspicuous white nodes on the superior portion of the culm. Along with the maturation, the natural green color of the culms becomes more evident and contrasts with the new sprouting shoots and the young culms of the following season. Those peculiar features turn $D$. asper as desired bamboo with a high ornamental value for horticulture ( $\mathrm{Li}$ and Kobayashi 2004; Banik 2016).

D. aspercan be propagated by seeds, culm cuttings, air-layering, offsets, macroproliferation, and micropropagation (Singh et al. 2012; Zang 2019). Although seeds can be an easy way to obtain seedlings, the flowering cycle of $D$. asper happens in intervals of around 30-100 years, and until now is an unpredictable phenomenon. When available, seeds have short viability and an unknown genetic background (Arya et al. 1999; Banik, 2016). Because of that, the vegetative propagation methods are the most practiced. However, they are infeasible on a large-scale plantlet demand due to the size of some propagules type and high labor and transport costs (Arya et al. 1999). Besides this, a fluctuation in rooting efficiency occurs over the seasons and between the genotypes (Ray and Ali 2017a).

For those reasons, micropropagation has consolidated as a process for large-scale quality plantlets production, with additional advantages for breeding, ex situ conservation, and basic research purposes. The bamboo in vitro culture establishment can be reached from different explants, as isolated zygotic embryos, whole seeds, shoot apex, nodal segments, leaves, roots, and inflorescences (Ojha et al., 2009). Inflorescences can be the last somatic resource to in vitro regeneration of selected genotypes in the case of monocarpic flowering (Arya et al., 2008). Due to the scarcity of that kind of explant, few papers reported the flowering tissue employment for bamboos micropropagation. In Table S1 is presented a summary of relevant reports of inflorescence tissue culture approaches for Bambusa's and Dendrocalamus' species over the last decades. Due to the rare availability of inflorescences, the present work aimed to establish a callus induction and plant regeneration through somatic embryogenesis from young inflorescences of Dendrocalamus asper.

\section{Material E Methods}

\section{Plant material}

Young inflorescence (pre-anthesis stages) of Dendrocalamus asper were collected at Fazenda dos Bambus $\left(-23.110470^{\circ} ;-48.368193^{\circ}\right)$, of the Jatobás Institute in the municipality of Pardinho, São Paulo, Brazil. Branches with young synflorescences (Fig. 1a) were collected along with the sporadic flowering of about 20 clumps in a plantation of 600 plants.

\section{Disinfestation and isolation of inflorescences}

The explant disinfestation method was carried out in three steps: (1) Branches containing developing synflorescences were selected. Prophylls and senescent glumes were removed before the branches were 
immersed in $70^{\circ} \mathrm{GL}$ ethanol for two minutes and transferred to sodium hypochlorite solution ( $2 \%$ active chlorine) with Tween ${ }^{\mathrm{TM}} 20$ (1 drop / $\left.100 \mathrm{ml}\right)$ and kept under constant stirring for 20 minutes. The branches were then rinsed twice with sterile deionized water and exposed for 10 minutes to the chamber's airflow on sterile filter paper for drying; (2) Synflorescences were excised from the branches and subjected to immersion in $70^{\circ} \mathrm{GL}$ ethanol for 30 seconds, followed by immersion in sodium hypochlorite solution ( $2 \%$ active chlorine) supplemented with Tween ${ }^{\mathrm{TM}} 20$ for 5 minutes, and then rinsed with sterile deionized water; (3) The central inflorescences of each synflorescence were selected and reduced by the removal of the lowermost glumes. Then, they were subjected to sodium hypochlorite solution ( $2 \%$ active chlorine) with Tween ${ }^{\mathrm{TM}} 20$ under agitation for 15 minutes, followed by a triple wash in sterile deionized water. Before inoculation, the inflorescences were subjected to a further size reduction, by removing 1 to 2 basal anthecia and the excision of the basal tissue damaged by chlorine.

\section{Callogenesis induction}

The basal culture media used for all the experiments consisted of the MS saline formulation (Murashige and Skoog, 1962), supplemented with $30 \mathrm{~g} . \mathrm{L}^{-1}$ of sucrose, $250 \mathrm{mg} \cdot \mathrm{L}^{-1}$ of polyvinylpyrrolidone, $2 \mathrm{ml} . \mathrm{L}^{-1}$ of Morel's vitamins (Morel and Wetmore, 1951), $1 \mathrm{~g} . \mathrm{L}^{-1}$ of glutamine, $1 \mathrm{~g} . \mathrm{L}^{-1}$ of Myo-inositol and 0.5 g. $\mathrm{L}^{-1}$ of hydrolyzed casein. The PGRs were added before the $\mathrm{pH}$ of the medium was adjusted to 5.8 . The media were sterilized by autoclaving for 15 minutes at $121^{\circ} \mathrm{C}$. Two subsequent induction experiments were carried out to determine: (1) the ideal 2,4-D concentration in combination with the cytokinins 2Isopentenyladenine (2-iP) or Kinetin (Kin), and (2) the effect of explant sectioning and its position onto the culture media. All the cultures were kept in the dark at $25 \pm 1{ }^{\circ} \mathrm{C}$.

\section{Exp. 1: Effects of 2,4-D combined with 2-iP or Kin}

After the disinfestation procedure, inflorescences were inoculated in culture media containing $0 \mu \mathrm{M}, 9 \mu \mathrm{M}$, $18 \mu \mathrm{M}, 27 \mu \mathrm{M}$, and $36 \mu \mathrm{M}$ 2,4-D in combination with $9 \mu \mathrm{M}$ 2-iP or $9 \mu \mathrm{M}$ Kin. That cytokinins concentration was settled based on the induction medium proposed by Yeh and Chang (1986a). The treatments consisted of 8 repetitions of a Petri dish $(60 \mathrm{~mm} \times 15 \mathrm{~mm})$, each containing 5 explants inoculated on 15 $\mathrm{ml}$ of culture medium. At 30 days after in vitro inoculation, the contamination rate, the callus induction rate, the oxidation rate, and the swelling of the explants were evaluated.

\section{Exp. 2: Effect of the explant sectioning and its position onto the medium}

After determining the ideal callus induction concentration, disinfested inflorescences were inoculated longitudinally sectioned or non-sectioned (entire). The sectioned explants were inoculated onto the medium in two ways: with the area exposed by the cut (1) upwards or (2) downwards, in contact with the culture medium. The treatments consisted of 20 repetitions of a Petri dish containing 4 explants inoculated on $15 \mathrm{ml}$ of culture medium. At 30 days after inoculation, the callus induction and oxidation rates were evaluated, and the obtained calli were characterized according to their morphology.

\section{Multiplication and differentiation}


Calli cultures maintained by two subcultures in the induction medium were transferred to multiplication media with $0 \mu \mathrm{M} ; 4.5 \mu \mathrm{M} ; 9 \mu \mathrm{M} ; 18 \mu \mathrm{M}$ 2,4-D. Those concentrations were proportional reductions of $100 \%$, $75 \%, 50 \%$, and $0 \%$ of the ideal dose of 2,4-D used for callus induction, as established in experiment 1 . At 30 days of transfer to the new treatments, the rate of oxidation, differentiation, and the frequency of each type of callus multiplied were evaluated.

\section{Statistical analysis}

Percentage data were obtained by averaging the binomial values of occurrence in each Petri dish. The analysis of variance assumptions was verified by analyzing the residues distribution of the model and the application of Bartlett's homoscedasticity test. When necessary, the percentage values were submitted to sine arc transformation. Statistical analyzes were performed in the R Studio environment ( $R$ 3.6.2). Variance analysis was performed using the "base", "stats" (R Core Team, 2019), and "agricolae" (Mendiburu, 2019) packages.

\section{Somatic embryos conversion and acclimatization}

Isolated and fused somatic embryos were transferred to the basal culture medium without PGR for maturation and plantlet conversion. The cultures were maintained for 15 days in the dark and subsequently exposed to the $16 \mathrm{~h}$ photoperiod for another 30 days. Finally, the obtained plantlets were subcultured to the basal medium in test tubes for 30 days for axillary branching, elongation, and root development before the acclimatization step. Then, the plantlets were transferred to $1 \mathrm{~L}$ pots containing a commercial substrate (Tropstrato FT - Vida Verde). Those plants were acclimatized in a $65 \%$ shading greenhouse under intermittent nebulization.

\section{Histochemical analysis}

Samples of induced inflorescences, histo-differentiated callus section, and isolated somatic embryos were fixed in glutaraldehyde for 48 hours. The material was dehydrated in an increasing ethanol series up to anhydrous conditions (Ruzin, 1999). Therefore, the samples were infiltrated and included in hydroxyethyl methacrylate (Leica Historesin, Germany). Cross-sectional and longitudinal sections of $5 \mu \mathrm{m}$ thickness were obtained in a rotating microtome RM 2125 (Leica, Germany) and stretched into slides. The sections were stained with toluidine blue in $\mathrm{pH} 6.8$ phosphate buffer according to O'Brien et al. (1964) for the observation and identification of anatomical structures. The images were captured in a DP71 camera attached to the BX-40 microscope (Olympus, Japan).

\section{Results And Discussion}

\section{Disinfestation and isolation of inflorescences}

The three-step disinfestation methodology and the closed-flowering compactness of the explants resulted in a high rate of viable cultures. In the first experiment, a contamination rate of only $4.2 \%$ was observed after 30 days of the in vitro introduction. In experiment 2, only $3.7 \%$ of the explants presented 
microorganisms manifestation. In both in vitro introductions, of these few contaminated explants, most of them manifested a late and slow-growing microorganism. Few cases of mycelial growth were observed.

Bamboos in vitro cultures are commonly recognized as hard-to-establish due to their microorganisms association and morphological characteristics, which usually can make disinfestation difficult (Tsay et al. 1990; Ray and Ali 2017b). Endogenous contamination is an important constraint during establishing bamboos in vitro cultures, mainly in explants obtained from mature and field-growth plants (Oprins et al. 2004). Lin et al. (2007), using D. latiflorus inflorescences for callus induction, reported the loss of $70 \%$ of explants due to contamination. Arya et al. (2008) reported the loss of $30 \%-40 \%$ of the explants due to contamination in the induction of shoots from $D$. asper inflorescences. Other studies that used inflorescences or isolated floral pieces from bamboo as explants did not report the contamination rates after disinfestation (Yeh and Chang, 1986a, 1986b; Lin et al., 2003; Lin et al., 2005; Qiao et al., 2013).

\section{Callus induction and oxidation}

In the first days after in vitro introduction, the swelling of the explants was observed, most notably in the treatments containing only cytokinin (2-iP or Kin). Rates of $52 \%$ and $25 \%$ of swollen explants were observed, respectively, in response to treatments containing only $9 \mu \mathrm{M}$ 2-iP or $9 \mu \mathrm{M}$ Kin. Yeh and Chang (1986 a, b) reported similar results of swelled explants during callus induction from two Bambusa species inflorescences. Cytokinins are plant growth regulators involved in many complex physiological mechanisms, playing an important role in cell enlargement and proliferation. During the anthesis, most of the spikelet subtending organs are in full-growing for anthers and stigma exsert, and susceptible to exogenous PGRs increases effects. Most of the explants in 2,4-D-free treatments showed tissue oxidation from the second subculture. The indeterminate flowering bamboos present inflorescences with a basal bud, which can regenerate new inflorescences, known as pseudospikelets (McClure, 1966). It is possible under in vitro conditions to revert the flowering process by shoots regeneration through exogenous hormonal stimulus, mainly by cytokinins PGRs (Ramanayake and Yakandawala, 1998; Arya et al. 2008). Another possible approach is the transfer of the flowering to the in vitro condition through the inflorescences' in vitro introduction and its further multiplication (Lin et al. 2003 b). Despite the $D$. asper having those kind of buds, its removal during the disinfestation procedure (glumes successive remotion and basal cutting before inoculation) impaired any direct inflorescence multiplication or shoot regeneration in the present study, even in the cytokinin alone treatment. The following flowering opportunities should consider pre-formed buds for in vitro inflorescence establishment, aiming for a continuous explant in vitro source.

Callus induction occurred exclusively in treatments containing 2,4-D, and most of them originated from the basal sectioned region of the inflorescences (Fig. 1b). An increase in the 2,4-D doses raised the callus induction rate, regardless of the combined cytokinin (Table 1). That effect was stronger in response to 2,4-D and 2iP, reaching the higher callus induction rate (77.5\%). Even though callogenesis was also induced in the 2,4-D combined with Kin, the auxin increment did not significantly increase the calli induction. The combination $18 \mu \mathrm{M}$ 2,4-D + $9 \mu \mathrm{M}$ 2iP was fixed as the ideal for callus induction due to the 
high induction effect associated with a low oxidation rate in the inflorescence explants. The 2,4-D has been reported for callogenesis and somatic embryogenesis in several bamboo species (Obsuwan et al., 2019). In young shoots of $D$. hamiltonii (Godbole et al., 2002) and zygotic embryos of $P$. edulis (Yuan et al., 2013), callus induction occurred only in a culture medium containing 2,4-D, and the induction frequency was affected by its concentration. For leaves, roots, and nodal segments of $D$. asper calli induction, it was necessary $30 \mu \mathrm{M}$ 2,4-D (Ojah et al. 2009). For inflorescences of $B$. oldhamii, D. latiflorus, and $D$. asper calli were obtained using 13.5-27 $\mu \mathrm{M}$ of 2,4-D on the culture medium (Prutpongse e Gavinlertvatana, 1992).

Table 1

Callus induction rate and oxidation rate of explants on the 30th day of Dendrocalamus asper inflorescences in vitro culture.

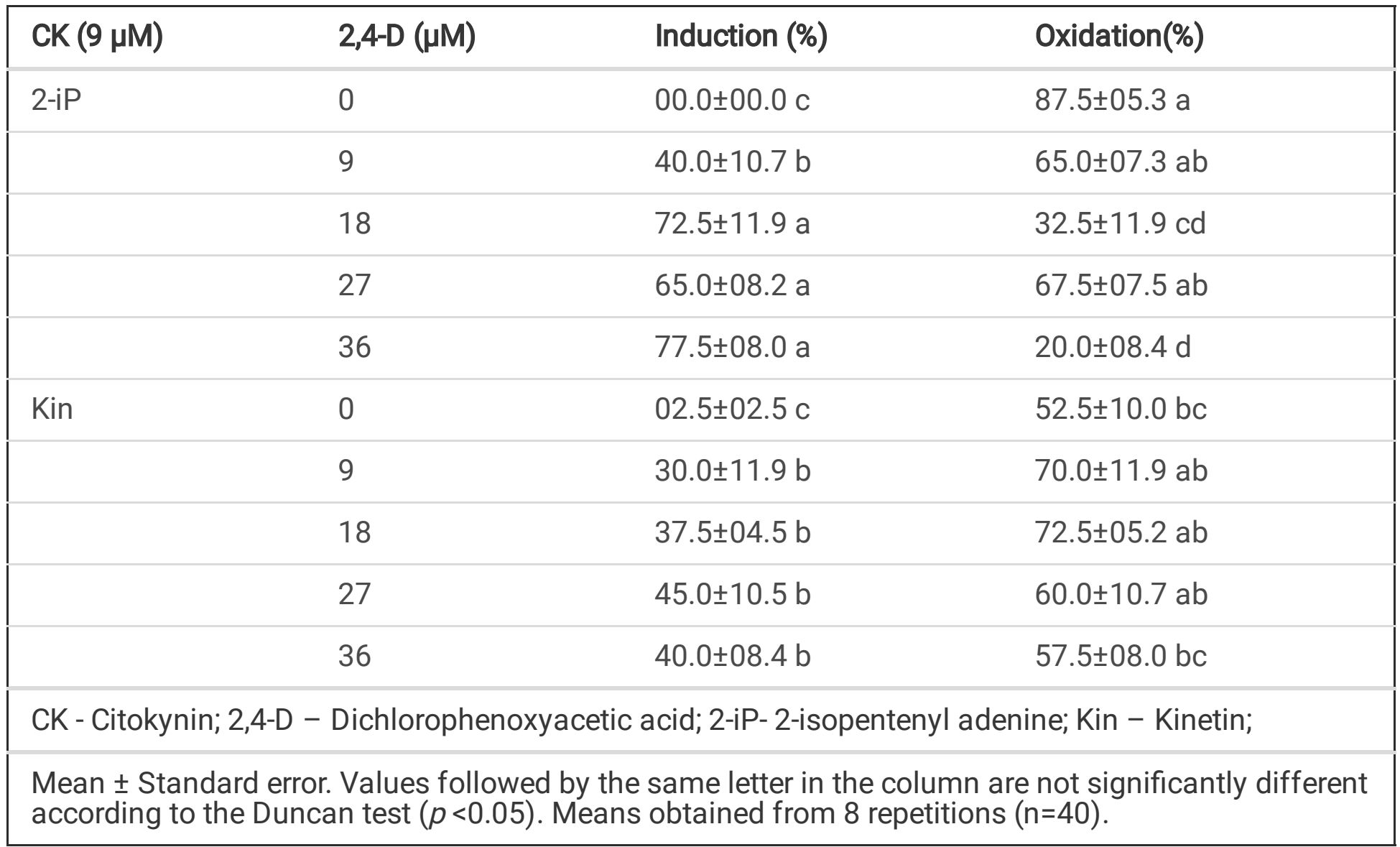

Histological sections of explants revealed a cell proliferation on floret subtending tissues (i.e., glume, palea, and lemma) after 7 days of induction (Fig. 3a). Those structures were membranous and vascularized, which in association with injury stress during the early stage can be suitable tissues for callus induction. Considering that the palea and lemma are two bract-like structures, i.e., a modified leaf (Lombardo and Yoshida 2015), we could very likely assume that the medium composition of our protocol might be successfully applied to other young vegetative explants as well.

\section{Calli morphology}


Most of the obtained cultures showed more than one type of calli, already in the first 30 days of induction (Fig. 1c). In general, three distinct types of calli were obtained: A less common but generally initial was a mucilaginous translucid callus with whitish cell clusters dissociated (Fig. 2a). The most common type 1 callus was translucid to yellowish with friable texture and small-nodular growth (Fig. 2c). The type 2 callus was yellowish to white, with a compact appearance and initial protoderm development, showing a smoother surface from where somatic embryos developed (Fig. 2e). A gradual and successive regeneration occurred among these calli. Type 1 callus could be obtained from the mucilaginous, and the type 2 embryogenic calli were usually derived from that primary one (Fig. 2b,d). Histological analysis of type 2-derived from type 1 callus revealed a protoderm organization around a meristematic center (Fig. 3b). Qiao et al. (2013) reported the development of embryogenic calli derived from primary calli generated from $D$. latiflorus anthers. The simultaneous different calli morphology occurrence was also reported for B. glaucescens (Jullien and Van, 1994). In general, type 1 callus was fast-growing and more prone to oxidation as compared to type 2 .

Few type- 1 calli had regenerated root clusters, probably originating from somatic embryos that were not classified as so during the selective subculture or even the direct root regeneration from type-1 callus. As soon as the roots touched the culture medium surface, a mucilaginous loose callus induction was observed, similar to the reported by Yeh and Chang (1986 b) and Chang and Lan (1995). That observation again highlights the potential of bamboo roots as a vegetative starting material for in vitro callus induction.

\section{Calli multiplication and histodifferentiation}

The combination of 2,4-D with the different cytokinins resulted in differential responses of the explants to oxidation occurrence and calli type produced (Table 2). When in combination with 2,4-D, 2-iP effectively promoted the induction of type 1 callus compared to Kin. In contrast, Kin reached the higher rate of type 2 callus in the 2,4-D free medium. Regardless of the cytokinin, the 2,4-D reduction to 4,5 $\mu \mathrm{M}$ or its total removal of the culture media promoted type 2 calli and the regeneration of somatic embryos. The type of cytokinin affected the oxidation rate of the cultures. In 2-iP alone-medium or in combination with reduced levels of 2,4-D (4.5 $\mu \mathrm{M} 2,4-\mathrm{D}+9 \mu \mathrm{M}$ de 2-iP), there was an increase in calli oxidation rates, especially on the type 1 calli. In the Kin-containing media, 2,4-D did not influence oxidation rates. The oxidation incidence is usually observed during the multiplication step of bamboo calli cultures. Qiao et al. (2013) reported the common occurrence of $D$. latiflorus anther-derived calli during the multiplication step. 
Table 2

Occurrence rates of type 1 and type 2 calli, morphogenetic differentiation, and oxidation of Dendrocalamus asper calli cultures derived from young inflorescence, during the somatic embryogenesis multiplication step.

\begin{tabular}{|c|c|c|c|c|c|}
\hline \multirow{2}{*}{$\begin{array}{l}\text { CK } \\
(9 \mu \mathrm{M})\end{array}$} & \multirow[t]{2}{*}{ 2.4-D ( $(\mu M)$} & \multicolumn{2}{|c|}{ Callus occurrence } & \multirow{2}{*}{$\begin{array}{l}\text { Differentiation } \\
\text { (\%) }\end{array}$} & \multirow{2}{*}{$\begin{array}{l}\text { Oxidation } \\
\text { (\%) }\end{array}$} \\
\hline & & Type 1 (\%) & Type 2 (\%) & & \\
\hline \multirow[t]{4}{*}{ 2-iP } & 0.0 & $44.4 \pm 06.1 \mathrm{bc}$ & $22.2 \pm 06.1 \mathrm{ab}$ & $16.7 \pm 09.9 a b$ & $55.6 \pm 06.1 \mathrm{a}$ \\
\hline & 4.5 & $72.2 \pm 13.8 \mathrm{ab}$ & $44.4 \pm 12.2 \mathrm{ab}$ & $22.2 \pm 09.6 a b$ & $16.7 \pm 09.9 a b$ \\
\hline & 9.0 & $94.4 \pm 4.81 \mathrm{a}$ & $27.8 \pm 08.9 a b$ & $22.2 \pm 06.1 a b$ & $5.56 \pm 04.8 b$ \\
\hline & 18.0 & $100.0 \pm 00.0 \mathrm{a}$ & $16.7 \pm 11.8 b$ & $16.7 \pm 11.8 a b$ & $00.0 \pm 00.0 \mathrm{~b}$ \\
\hline \multirow[t]{4}{*}{ Kin } & 0.0 & $25.9 \pm 08.8 c$ & $58.3 \pm 11.8 \mathrm{a}$ & $43.7 \pm 08.3 \mathrm{a}$ & $27.1 \pm 12.6 \mathrm{ab}$ \\
\hline & 4.5 & $90.5 \pm 08.9 a$ & $33.3 \pm 09.6 \mathrm{ab}$ & $00.0 \pm 00.0 \mathrm{~b}$ & $23.8 \pm 13.1 \mathrm{ab}$ \\
\hline & 9.0 & $71.4 \pm 10.6 \mathrm{ab}$ & $09.5 \pm 08.9 b$ & $09.5 \pm 05.7 b$ & $33.3 \pm 13.6 \mathrm{ab}$ \\
\hline & 18.0 & $25.0 \pm 17.7 c$ & $25.0 \pm 11.3 \mathrm{ab}$ & $00.0 \pm 00.0 \mathrm{~b}$ & $58.3 \pm 17.7 \mathrm{a}$ \\
\hline \multicolumn{6}{|c|}{ CK - Citokynin; 2,4-D - Dichlorophenoxyacetic acid; 2-iP- 2-isopentenyl adenine; Kin - Kinetin. } \\
\hline
\end{tabular}

From the second subculture on the induction medium, type 2 callus, inflorescence-like structures (Fig. 1d), and somatic embryos were regenerated (Fig. 1e-f). In induced callus from $D$. latiflorus anthers, shoots were obtained during the induction step (Qiao et al. 2013). Yeh e Chang (1986 b) reported the somatic embryos' regeneration during the 16 months long culture on 2,4-D and Kin-containing medium. In the present work, an increase in the cytokinin:auxin ratio promoted differentiation of structures on type 2 callus and subsequent differentiation of somatic embryos. Similar observations occurred for $D$. hamiltonii with the gradual reduction of 2,4-D and NAA concomitant with BAP increases in the culture medium (Godbole et al., 2002). As for many plant calli cultures, a higher cytokinin concentration than auxin in bamboos can enhance the shoots and embryos regeneration. In bamboos calli cultures, a concentrationratio of 2:1 (cytokinin: auxin) was feasible to regenerate shoots (Prutpongse and Gavinlertvatan 1992).

\section{Explant sectioning}

The longitudinal sectioning of inflorescences further increased the callus induction rates than nonsectioned inflorescences (Table 3). The orientation of these half-inflorescences onto the culture medium also influenced the callus induction rates. The cut-surface inoculation in contact with the culture medium (downward cutting) reduced the callus induction rate. The inoculation of half-inflorescence in an upward cutting position resulted in a significant increment in the callus induction rate, resulting in a callus induction in almost $100 \%$ of the explants. The explant sectioning and its inoculate position onto the medium did not influence the contamination rates observed. Regardless of the treatment, most calli 
started on the sectioned basal region of the inflorescence. Similar observations were reported (Godbole et al. 2002), in which initial swelling and cellular proliferation began from the cut ends segmented shoots of D. hamiltonii. Explants inoculated with cut sections upward oriented developed calli from the borders. It was also observed callus initiation from the anthers. After 30 days, a subsequent subculture on the same induction medium of those anther-derived calli resulted in oxidation, and embryonic callus (type 2) was not observed. Although anther-derived callus could result in haploid plants, interesting for breeding purposes (Tsay et al. 1990), the low induction rate compared to the enclosing tissues of inflorescences showed the need for improvement on the induction procedure in anthers. The inflorescence longitudinal section enhanced the induction rate by relieving the physical blocking of the enclosing tissues of spikelets. Additionally, mechanical wounding is recognized and commonly adopted for cellular differentiation induction by overexpression of stress-related genes (Fehér et al. 2003; Wójcik et al. 2020). Furthermore, the explant size-reduction increases the surface-area-to-volume ratio, promoting the stress triggered by the in vitro environment. Large explants or intact organs can show, even that explanted, a well-organized symplastic pathway and stable cellular metabolism, which can lead to recalcitrance to in vitro responses. The wounding of tissues often results in symplastic domain rupture and can stimulate the establishment of new domains and plasmodesmata cell-to-cell communication, promoting differentiation and pluripotentiality expression (Bonga, 2016). Even though the small size of the inflorescences used as explants for those experiments, the sectioning showed a feasible and straightforward technique to increase the explant number, callus induction area, and the callus induction rate. This result suggests that using the thin cell layer technique may be beneficial to increase callus induction from bamboo spikelets.

Table 3

Callus induction and explant contamination rates of Dendrocalamus asperyoung inflorescences in the function of longitudinal section and the explant orientation on the culture medium.

\begin{tabular}{|llll|}
\hline Longitudinal sectioning & Explant orientation inoculation & $\begin{array}{l}\text { Induction } \\
(\%)\end{array}$ & $\begin{array}{l}\text { Contamination } \\
\text { (\%) }\end{array}$ \\
\hline- & Non-sectioned & $80,4 \pm 04,5 \mathrm{~b}$ & $05,0 \pm 02,3 \mathrm{a}$ \\
\hline+ & Downward cutting & $63,3 \pm 06,7 \mathrm{c}$ & $03,7 \pm 02,0 \mathrm{a}$ \\
\hline+ & Upward cutting & $98,7 \pm 01,2 \mathrm{a}$ & $02,5 \pm 01,7 \mathrm{a}$ \\
\hline
\end{tabular}

Mean \pm Standard error. Values followed by the same letter in the column are not significantly different according to the Duncan test $(p<0.05)$. Means obtained from 20 repetitions $(n=80)$.

\section{Secondary somatic embryogenesis}

A scutellum deformation was observed when somatic embryos were kept in a multiplication medium containing the higher 2,4-D levels ( $9 \mu \mathrm{M}$ to $18 \mu \mathrm{M})$. That occurred mainly on somatic embryos in late developmental stages. The scutellar tissue of zygotic and somatic embryos was 2,4-D-responsive for other Dendrocalamus species (Sumathi et al. 2003; Zhang et al., 2010). In our work, during the selective multiplication, easily detached and rounded-shaped somatic embryos were subcultured isolated on 18 
$\mu \mathrm{M}$ 2,4-D + $9 \mu \mathrm{M}$ 2-iP (induction medium). Just a minor growth on the root region of the embryo axis was observed. At the same time, a distinguished cellular proliferation occurred around the somatic embryo axis, specifically on the scutellum tissue, where it was possible to observe meristematic centers (Fig. 3c). That observation led to an understanding of the origin of scutellum-fused embryos clusters and evidenced the 2,4-D inducing effect of secondary embryogenesis in the scutellum tissues. The maintenance of embryogenic calli in 2,4-D containing media leads to secondary embryogenesis from the regenerated embryos. Plant regeneration from these fused embryo clusters (Fig. 2f) was inefficient because of their non-synchronic maturation. Long-term cultivation on a 2,4-D-containing medium led to clusters of reduced-size fused somatic embryos, which were unable to maturation and plant regeneration. Therefore, a further study focusing on the control of secondary somatic embryogenesis is suggested to improve normal embryo regenerating rates and control the repetitive multiplication step.

\section{Plantlet's regeneration}

Somatic embryos regenerated in all the tested media during the multiplication step. Normal somatic embryos had translucent to white color showing a regular rounded to spherical shape with the embryonal axis detached on their central region. Most of them were easily detachable from the callus surface. The conversion of plantlets occurred faster in round somatic embryos with smooth epidermis than those with the rough epidermis or fused scutellum (Fig. 2f). Greening of the embryonic axis was observed after 7-10 days of $16 \mathrm{~h}$ photoperiod exposition, and shoots and roots developed after 10-14 days. Histochemical analysis showed a considerable starch accumulation in the scutellum tissue (Fig. 3d), which probably provoked the yellowish to the white color of the somatic embryos. Similar features were observed in Phyllostachys edulis somatic embryos (Yuan et al. 2013). That increased starch content on scutellum tissue was probably due to the sucrose enriched medium and the lack of endosperm and aleurone layer on somatic embryos. Both structures are primarily responsible for the starch accumulation and starch related-enzymes in seeds. In somatic embryos of $D$. hamiltonii, the scutellum substituted those structures in the amylase accumulation and starch deposition (Godbole et al. 2004). In the present work, the successfully converted plantlets were transferred to test tubes with the basal medium, where synchronous rooting and shoot elongation was observed. The typical broad-leaves development of embryonic seedlings was also observed during the plantlet elongation (Fig. 1g). After 45 days, converted plants started tillering and were acclimatized (Fig. 1h).

\section{Conclusions}

The present work described a somatic embryogenesis protocol from young inflorescences of the giant bamboo, Dendrocalamus asper (Fig. S1). A 3-step disinfestation procedure using ethanol and sodium chlorine in inflorescence explants allowed more than $95 \%$ of explants to be successfully in vitro introduced. That procedure, combined with the embryogenic competence of the young enclosing tissues of inflorescence, resulted in an efficient in vitro callus culture establishment. 2,4-D was essential for callus induction, and the cytokinins tested influenced the type of callus obtained from inflorescences, which was correlated with their embryogenic capacity. The longitudinal sectioning of inflorescences before 
inoculation further increased the callus induction rate and the number of initial explants, improving the efficiency of in vitro introduction. When combined with 2-iP or Kin, the 2,4-D concentration reduction resulted in a rapid somatic embryos regeneration from the obtained calli. Those results corroborated the already known benefits of Kin utilization for bamboo micropropagation and introduced the 2-iP as a feasible cytokinin alternative for bamboo somatic embryogenesis from inflorescence explants. The subculture of the embryos to the induction medium led to secondary embryogenesis from scutellum tissues, resulting in fused and asynchronous embryos maturation. The somatic embryos obtained were converted into plantlets in a PGR-free medium. Embryogenic cultures induced from inflorescences allow the large-scale propagation of selected genotypes. They are also an important method for rescue and ex situ conservation of elite genotypes in a monocarpic flowering event. The results presented here are important to the scale-up multiplication of this multipurpose bamboo, emphasizing the ornamental industry.

\section{Declarations}

Funding: Funding for this research was provided by the Conselho Nacional de Desenvolvimento Científico e Tecnológico - CNPq (Proc. n 457726/2013-0, 302798/2018-8, 407974/2018-0 and 140562/2016-8) and by Coordenação de Aperfeiçoamento de Pessoal de Nível Superior (CAPES).

Conflict of interests: The authors declare that they have no conflict of interest.

Ethics approval: All the experiments undertaken in this study comply with the current laws of the country where they were performed.

Data availability: All data generated or analysed during this study are included in this published article

\section{Authors Contribution}

All authors contributed to the study conception and design. Material preparation, data collection and analysis were performed by Thiago Sanches Ornellas, Yohan Fritsche, and Edison Cardona Medina. The first draft of the manuscript was written by Thiago Sanches Ornellas and all authors commented on previous versions of the manuscript. All authors read and approved the final manuscript.

\section{Acknowledgments}

We are grateful to Coordenação de Aperfeiçoamento de Pessoal de Nível Superior - Brasil (CAPES), Brasília, Brazil for the scholarships to TSO and ECM. We also thank the Conselho Nacional de Desenvolvimento Científico e Tecnológico, Brasília, Brazil (CNPq Proc. n 457726/2013-0, 302798/20188, and 407974/2018-0) for the financial support, and CNPq (proc 140562/2016-8) for the scholarship to YF. We appreciate the Instituto Jatobás, for providing the Dendrocalamus asperflowering branches to the present study, and Thiago Machado Greco and Guilherme Korte for communicating our group about the 
flowering plants. Finally, our deepest gratitude to Associação Catarinense do Bambu (BambuSC) for all support during the development of the project "Tecnologias para o Desenvolvimento Sustentável da Cadeia Produtiva do Bambu no Sul do Brasil".

\section{References}

Akinlabi ET, Anane-Fenin K, Akwada DR (2017) Applications of Bamboo. In: Akinlabi ET, Anane-Fenin K, Akwada DR (eds) Bamboo: The Multipurpose Plant. Springer, Cham, pp 179-

219. https://doi.org/10.1007/978-3-319-56808-9_5

Arya S, Sharma S, Kaur R, Dev Arya I (1999) Micropropagation of Dendrocalamus asper by shoot proliferation using seeds. Plant Cell Reports 18:879-882. https://doi.org/10.1007/s002990050678

Arya S, Satsangi R, Arya ID (2008) Direct regeneration of shoots from immature inflorescences in Dendrocalamus asper (edible bamboo) leading to mass propagation. Bamboo Science \& Culture 21:1420.

Banik RL (2016) Dendrocalamus Nees. In: Banik RL (ed) Silviculture of South Asian Priority Bamboos. Tropical Forestry. Springer, Singapore, pp 177-192. https://doi.org/10.1007/978-981-10-0569-5_4

Chang WC, Lan TH (1995) Somatic embryogenesis and plant regeneration from roots of bamboo (Bambusa beecheyana Munro var. beecheyana). Journal of Plant Physiology 145:535538. http://doi.org/10.1016/S0176-1617(11)81784-0

Clark LG., Oliveira RP (2018) Diversity and evolution of the new world bamboos (Poaceae: Bambusoideae: Bambuseae, Olyreae). In: Proceedings of the $11^{\text {th }}$ World Bamboo Congress, Xalapa, Mexico. The World Bamboo Organization, Plymouth, pp. 35-47.

Gillis K, Gielis J, Peeters H, Dhooghe E, Oprins J (2007) Somatic embryogenesis from mature Bambusa balcooa Roxburgh as basis for mass production of elite forestry bamboos. Plant Cell Tiss Organ Cult 91:115-123.

Godbole S, Sood A, Thakur R, Sharma M, Ahuja PS (2002) Somatic embryogenesis and its conversion into plantlets in a multipurpose bamboo, Dendrocalamus hamiltonii Nees et Arn. Ex Munro. Current Science 83:885-889. http://www.jstor.org/stable/24107094

Godbole S, Sood A, Sharma M, Nagar PK, Ahuja PS (2004) Starch deposition and amylase accumulation during somatic embryogenesis in bamboo (Dendrocalamus hamiltonii). Journal of Plant Physiology 161:245-248. http://doi.org/10.1078/0176-1617-01219

Jullien F, Van KTT (1994) Micropropagation and embryoid formation from young leaves of Bambusa glaucescens' Golden Goddess'. Plant Science 98:199-207. https://doi.org/10.1016/0168-9452(94)900108 
Li Z, Kobayashi M (2004) Plantation future of bamboo in China. J. of For. Res. 15:233242. https://doi.org/10.1007/BF02911032

Liese W, Welling J, Tang TKH (2015) Utilization of Bamboo. In: Liese W, Köhl M (eds) Bamboo: The Plant and its Uses. Springer, Switzerland, pp 299-346 .https://doi.org/10.1007/978-3-319-14133-6_10

Lin CC, Lin CS, Chang WC (2003 a) In vitro flowering of Bambusa edulis and subsequent plantlet survival. Plant Cell, Tissue and Organ Culture 72:71-78. https://doi.org/10.1023/A:1021281217589

Lin CS, Chen CT, Lin CC, Chang WC (2003b) A method for inflorescence proliferation. Plant cell reports, 21:838-843. https://doi.org/10.1007/s00299-003-0571-3

Lin CS, Lin CC, Chang WC (2005) Shoot regeneration, re-flowering and post flowering survival in bamboo inflorescence culture. Plant Cell Tiss Organ Cult 82:243-249. https://doi.org/10.1007/s11240-005-0883-9

Lin CS, Liang CJ, Hsaio HW, Lin MJ, Chang WC (2007) In vitro flowering of green and albino Dendrocalamus latiflorus. New Forests 34:177-186.

https://doi.org/10.1007/s11056-007-9045-8

Lombardo F, Yoshida $\mathrm{H}$ (2015) Interpreting lemma and palea homologies: a point of view from rice floral mutants. Frontiers in Plant Science 6:61. https://doi.org/10.3389/fpls.2015.00061

McClure FA (1966) A glossary of the bamboos. Taxon 15:220-235. https://doi.org/10.2307/1215968

Mendiburu F (2019) Agricolae: Statistical Procedures for Agricultural Research. R package version 1.31. https://cran.r-project.org/package=agricolae

Morel G, Wetmore RH (1951) Fern callus tissue culture. American Journal of Botany 38:141143. https://doi.org/10.2307/2437837

Murashige T, Skoog F (1962) A revised medium for rapid growth and bio assays with tobacco tissue cultures. Physiologia Plantarum 15:473-497.

O'Brien T, Feder N, McCully ME (1964) Polychromatic staining of plant cell walls by toluidine blue 0. Protoplasma 59:368-373. https://doi.org/10.1007/BF01248568

Obsuwan K, Duangmanee A, Thepsithar C (2019) In vitro propagation of a useful tropical bamboo, Thyrsostachys siamensis Gamble, through shoot-derived callus. Horticulture, Environment, and Biotechnology 60:261-267. https://doi.org/10.1007/s13580-018-00119-z

Ojha A, Verma N, Kumar A (2009) In vitro micropropagation of economically important edible bamboo (Dendrocalamus asper) through somatic embryos from root, leaves and nodal segments explants. Res Crops, 10:430-436. 
Oprins J, Grunewald W, Gillis K, Delaere P, Peeters H, Gielis J (2004) Micropropagation: a general method for commercial bamboo production. In: Proceedings of the $7^{\text {th }}$ World Bamboo Congress, New Delhi, India. The World Bamboo Organization, Plymouth, pp. 1-11.

Paudyal K, Adhikari S, Sharma S, Samsudin YB, Paudyal BR, Bhandari A, Birhane E; Darcha G; Trinh TL, Baral H (2019) Framework for assessing ecosystem services from bamboo forests: Lessons from Asia and Africa 255 CIFOR. http://doi.org/10.17528/cifor/007433

Prutpongse P, Gavinlertvatana P (1992) In vitro micropropagation of 54 species from 15 genera of bamboo. HortScience 27:453-454. https://doi.org/10.21273/HORTSCI.27.5.453

Qiao G, Li H, Liu M, Jiang J, Yin Y, Zhang L, Zhuo R (2013) Callus induction and plant regeneration from anthers of Dendrocalamus latiflorus Munro. In vitro Cellular \& Developmental Biology-Plant 49:375382. https://doi.org/10.1007/s11627-013-9498-8

Qiao G, Yang H, Zhang L, Han X, Liu M, Jiang J, Jiang Y, Zhuo R (2014) Enhanced cold stress tolerance of transgenic Dendrocalamus latiflorus Munro (Ma bamboo) plants expressing a bacterial CodA gene. In vitro Cellular \& Developmental Biology-Plant 50:385-391. https://doi.org/10.1007/s11627-013-9591-z

R Core Team (2019). R: A language and environment for statistical computing. R Foundation for Statistical Computing, Vienna, Austria. https://www.R-project.org/

Ramanayake SMSD., Yakandawala K (1998) Incidence of Flowering, Death and Phenology of Development in the Giant Bamboo (Dendrocalamus giganteus Wall. ex Munro). Annals of Botany 82:779785. https://doi.org/10.1006/anbo.1998.0754

Ramanayake SMSD, Wanniarachchi WAVR (2003) Organogenesis in callus derived from an adult giant bamboo (Dendrocalamus giganteus Wall. ex Munro). Scientia Horticulturae 98:195200. http://doi.org/10.1016/S0304-4238(02)00204-2

Ray SS, Ali MN (2017a) Factors affecting macropropagation of bamboo with special reference to culm cuttings: a review update. N.Z. j. of For. Sci. 47, 17. https://doi.org/10.1186/s40490-017-0097-z

Ray SS, Ali N (2017b) Biotic Contamination and Possible Ways of Sterilization: A Review with Reference to Bamboo Micropropagation. Brazilian Archives of Biology and Technology 60:1-

11. https://doi.org/10.1590/1678-4324-2016160485

Ruzin, S. E. (1999). Plant microtechnique and microscopy. Oxford University press.

Singh SR, Dalal S, Singh R, Dhawan AK, Kalia RK (2012) Micropropagation of Dendrocalamus asper \{Schult. \& Schult. F.\} Backer ex k. Heyne): an exotic edible bamboo. J. Plant Biochem. Biotechnol 21:220228. https://doi.org/10.1007/s13562-011-0095-9 
Singh SR, Singh R, Kalia S, Dalal S, Dhawan AK, Kalia RK (2013) Limitations, progress and prospects of application of biotechnological tools in improvement of bamboo-a plant with extraordinary qualities. Physiol Mol Biol Plants 19:21-41. https://doi.org/10.1007/s12298-012-0147-1

Soreng RJ, Peterson PM, Romaschenko K, Davidse G, Teisher JK, Clark LG, Barberá P, Gillespie LJ, Zuloaga FO (2017) A worldwide phylogenetic classification of the Poaceae (Gramineae) II: An update and a comparison of two 2015 classifications. Journal of Systematics and Evolution, 55:259290. https://doi.org/10.1111/jse.12262

Sumathi R, Malliga P, Yashodha R, Gurumurthy K (2003) Enhanced somatic embryogenesis and plant regeneration in bamboo (Dendrocalamus strictus). Plant Cell Biotechnol. Mol. Biol 4:9-16.

Tsay HS, Yeh CC, Hsu JY (1990) Embryogenesis and plant regeneration from anther culture of bamboo (Sinocalamus latiflora (Munro) McClure). Plant Cell Reports 9:349351. https://doi.org/10.1007/BF00232396

Tsay HS, Hsu JY, Yeh CC (1996) Haploidy in bamboo (Sinocalamus latiflora) by anther culture. In: Jain S.M., Sopory S.K., Veilleux R.E. (eds) In: In Vitro Haploid Production in Higher Plants. Current Plant Science and Biotechnology in Agriculture, vol 25. Springer, Dordrecht. https://doi.org/10.1007/978-94017-1858-5_17

Wang Y, Qu H, Bai T, Chen Q, Li X, Luo Z, Lv B, Jiang M (2021) Effects of Variations in Color and Organ of Color Expression in Urban Ornamental Bamboo Landscapes on the Physiological and Psychological Responses of College Students. International Journal of Environmental Research and Public Health, 18:1151. https://doi.org/10.3390/ijerph18031151

Wójcik AM, Wójcikowska B, Gaj MD (2020) Current perspectives on the auxin-mediated genetic network that controls the induction of somatic embryogenesis in plants. International journal of molecular sciences, 21:1333. https://doi.org/10.3390/ijms21041333

Yeh ML, Chang WC (1986 a) Plant regeneration through somatic embryogenesis in callus culture of green bamboo (Bambusa oldhamii Munro). Theoret. Appl. Genetics 73:161163. https://doi.org/10.1007/BF00289269

Yeh ML, Chang WC (1986 b) Somatic embryogenesis and subsequent plant regeneration from inflorescence callus of Bambusa beecheyana Munro var. beecheyana. Plant cell reports 5:409-411.

htpp:///doi.org/10.1007/BF00269626

Yuan JL, Yue JJ, Wu XL, Gu XP (2013) Protocol for callus induction and somatic embryogenesis in Moso bamboo. PloS one 8(12):e81954 . https://doi.org/10.1371/journal.pone.0081954

Yuan J, Gu X, Li L, Yue J, Yao N, Guo G (2009) Callus induction and plantlet regeneration of Bambusa multiplex. Scientia Silvae Sinicae 45:35-39 (available in Chinese, abstract in English) 
Zang Q, Liu Q, Zhuge F, Wang X, Lin X (2019) In vitro regenerations via callus induction in Dendrocalamus asper (Schult.) Backer. Propagation of Ornamental Plants 19:66-71.

Zhang N, Fang W, Shi Y, Liu Q, Yang H, Gui R, Lin X (2010) Somatic embryogenesis and organogenesis in Dendrocalamus hamiltonii. Plant Cell Tiss Organ Cult 103:325-332. https://doi.org/10.1007/s11240010-9783-8

Zheng J, Tarin MWK, Jiang D, Li M, Ye J, Chen L, He T, Zheng Y (2021) Which ornamental features of bamboo plants will attract the people most?. Urban Forestry \& Urban Greening 61:127101. https://doi.org/10.1016/j.ufug.2021.127101

\section{Figures}
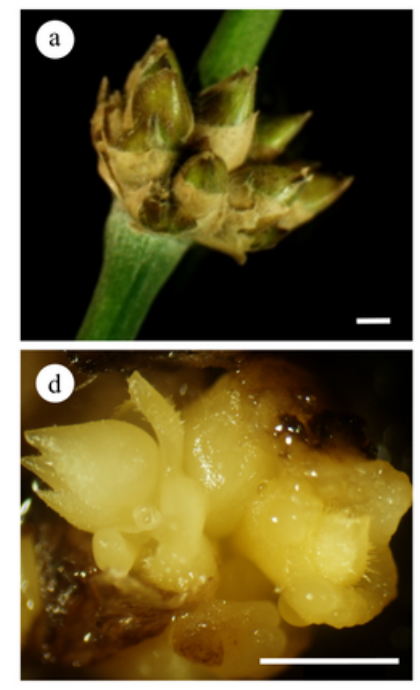
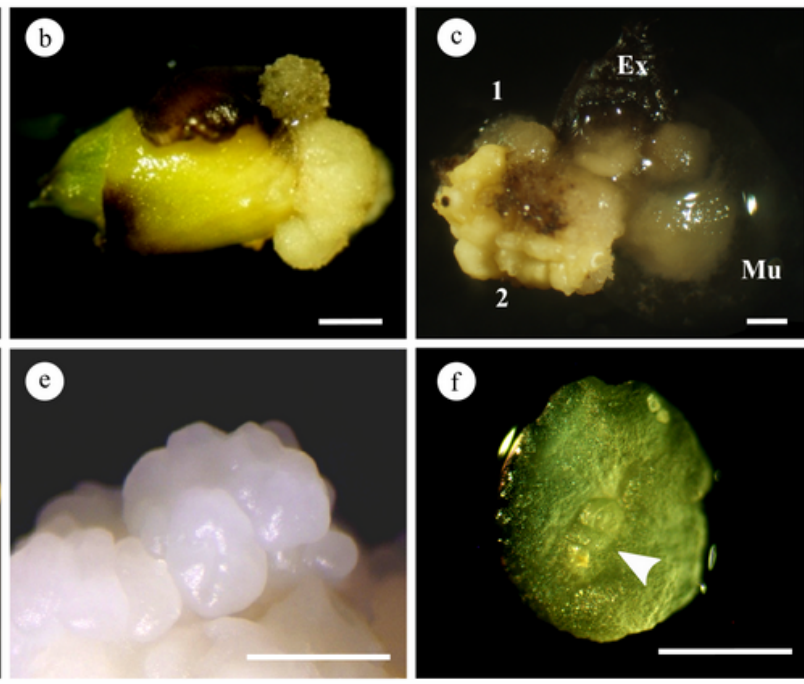
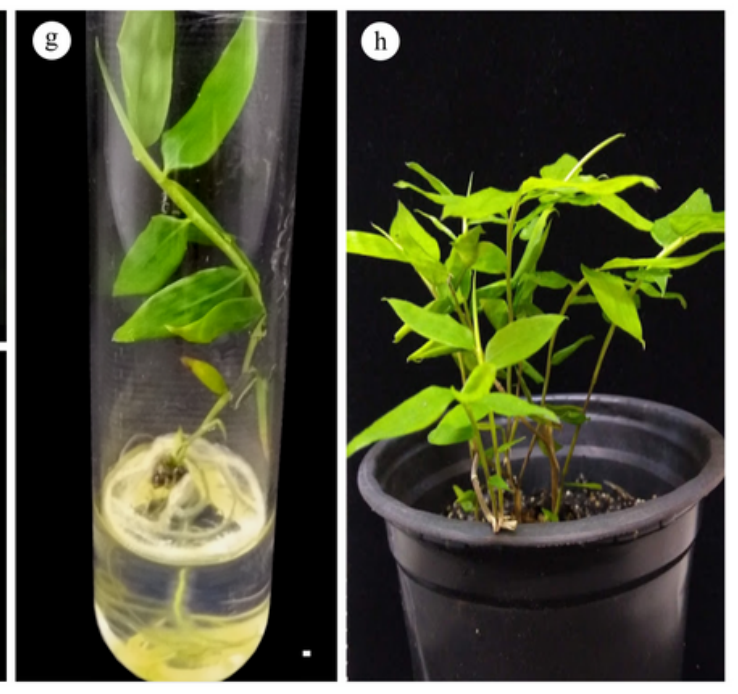

\section{Figure 1}

Somatic embryogenesis from young inflorescences of Dendrocalamus asper. (a) Synflorescence; (b) Callus induction on the basal region of inflorescence after 30 days of the in vitro introduction. (c) The different callus morphology obtained from inflorescence at the 60th day of induction, 1- Type 1 callus, 2Type 2 callus, Mu-Mucilaginous callus, Ex-Oxidated explant; (d) Type 2 callus regenerating inflorescencelike structure. (e) Somatic embryos; (f) Somatic embryo with foregrounded embryonic axis (arrowhead); (g) Somatic embryo-converted plantlet; (h) Acclimatized plantlet. Bars $=1 \mathrm{~mm}$ 2

\section{Figure 2}

Dendrocalamus asper inflorescence-derived calli types. (a) Mucilaginous callus; (b) Type 1 callus regenerating from a mucilaginous callus; (c) Type-1 callus; (d) Type-2 callus regenerating from type-1 callus; (e) Type-2 callus regenerating somatic embryo; (f) Secondary somatic embryogenesis on a scutellum tissue of a fused converting somatic embryos cluster. Bars $=2 \mathrm{~mm}$ 


\section{a}
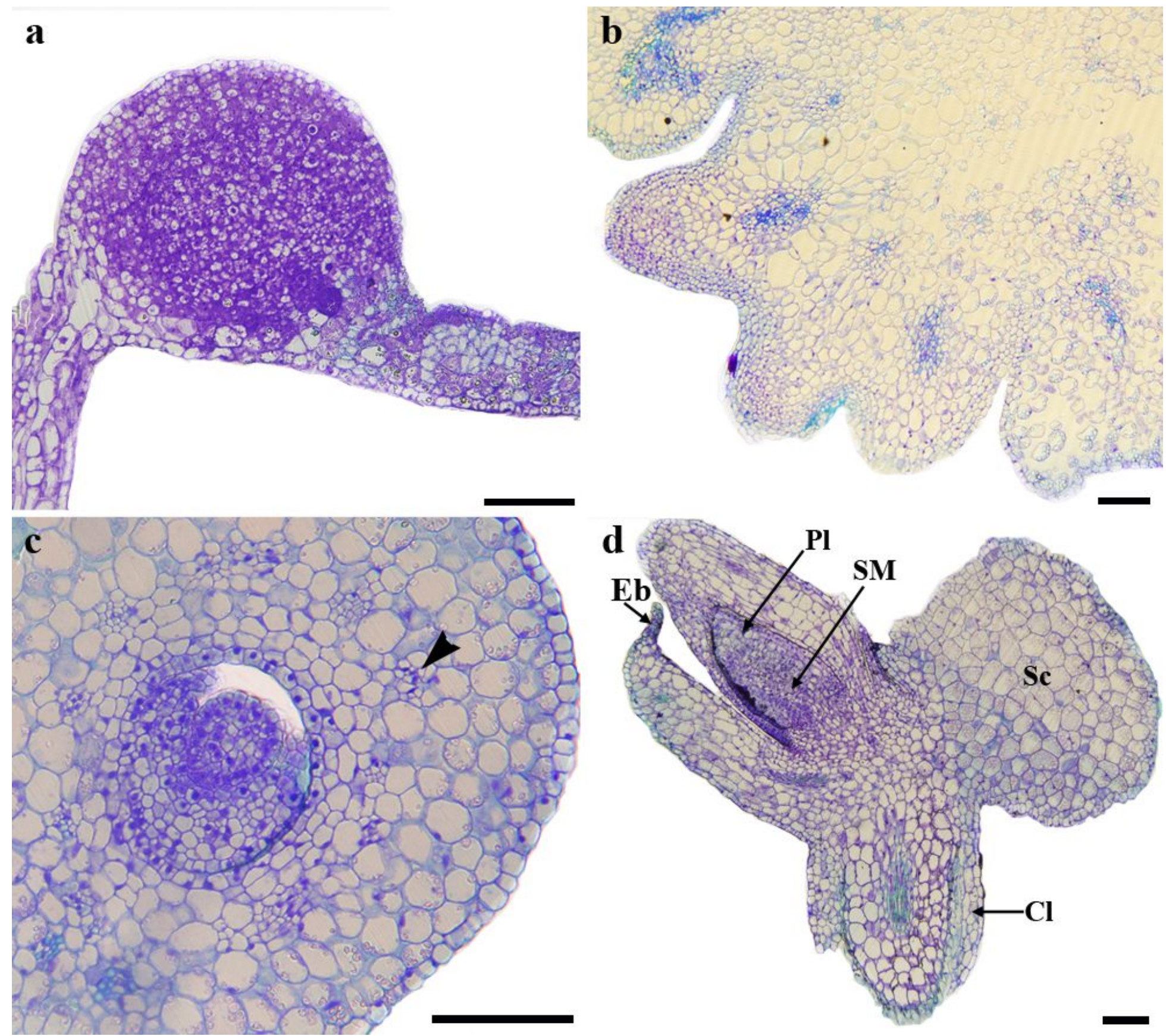

\section{Figure 3}

Histological analysis in Dendrocalamus asper calli and somatic embryo obtained from young inflorescences. (a) Longitudinal section of initial callogenesis in the inflorescence lemma tissue at 7th day of in vitro induction; (b) Longitudinal section of Type 2 callus with an organized protoderm developing from a type 1 callus; (c) Cross-section of the scutellar somatic embryo showing meristematic centers around the embryo axis (arrowhead); (d) Longitudinal section of a somatic embryo, ScScutellum, PI- Plumule, SM-Shoot Meristem, Eb- Epiblast, Cl- Coleorhiza. Bars $=100 \mu \mathrm{m}$

\section{Supplementary Files}


This is a list of supplementary files associated with this preprint. Click to download.

- Supplementarydata.docx 